\section{Electron Density Profiles in the lonosphere}

IN many parts of the world during the past twenty years, regular measurements have been made of the maximum electron density $\left(N_{m}\right)$ and the approximate true height $\left(h_{m}\right)$ of the various layers in the ionosphere. Both these parameters can be obtained fairly easily from the $h^{\prime}(f)$ curves (ionograms) which are produced by automatic pulse-sounding equipment. On the other hand, very little accurate information is available on $N(h)$ profiles, the distribution of electron density with height in the ionosphere, and how these profiles vary with time, season and geographical location. Correspondingly, little is known about the variation of electron density with time at a constant height (the $N(t)$ curve). The ionograms contain all this information, but the mathematical procedure for deriving it explicitly is very laborious, especially if the effect of the geomagnetic field is taken into account. The electronic computers now available have opened up a new era in this field since they can readily be used to compute $N(h)$ profiles from ionograms.

A programme of such computations has been organized by the Radio Research Station of the Department of Scientific and Industrial Research, at Slough, as part of the United Kingdom programme of observations during the International Geophysical Year. The $N(h)$ profiles are being produced by Ferranti, Ltd., on a "Pegasus" automatic digital computer using $h^{\prime}(f)$ data obtained at four observatories, namely, Slough, Ibadan, Singapore, and Port Stanley. For each observatory profiles are being calculated for each hour of the day for about four days a month beginning in July 1957 . When the ionograms are suitable, Regular World Days are selected for analysis; when this is not practicable, other days are substituted. This programme will be continued until December 1958 when the possibility of extending the work will be considered. The analysis is carried out according to a method recently described by Thomas, Haselgrove and Robbins (J. Atmos. Terr. Phys., 13, 46 ; 1958), which makes no a priori assumptions about the variation of electron density with height except that it increases monotonically. It can be applied to $h^{\prime}(f)$ curves from any observatory merely by changing the geomagnetic dip angle and the gyro-frequency, both of which are teken into account, in the calculations.

\section{The Association of Universities of the British Com- monwealth}

THE report for $1956-57$ of the Executive Council of the Association of Universities of the British Commonwealth (pp. 25. London, 1958), to which are appended a note on the Committee of ViceChancellors and Principals of the Universities of the United Kingdom (which met eleven times during the year) and the accounts of the Association, records expenditure of $£ 24,797$ and an income of only $£ 26,980$ compared with $£ 27,860$ for $1955-56$. Lists of names and other particulars of overseas students continued to be collected from all universities and university colleges in the United Kingdom and a statistical analysis of this material has been printed as an appendix to the Commonwealth Universities Year Book for 1958. These lists are available for consultation by accredited inquirers and the Association also maintains a collection of up-to-date issues of official publications of Commonwealth universities, which are available in the office for reference by inquirers. During the year the Association acted in connexion with 408 appointments in member universities outside the United Kingdom, compared with 394 in 1955-56, and handled 2,871 inquiries in relation to specific vacancies, compared with 2,962 in 1955-56. A list of posts in respect of which the Association was requested to take action is included. The Association has also assisted in the administration of the Marshall Scholarships, the Beaverbrook Scholarships, the Commonwealth University Interchange and in the award of British Memorial Scholarships for study in Australia and Imperial Relations Trust Fellowships.

\section{European Interchange Scheme for Postgraduate Students}

THE Department of Scientific and Industrial Research is encouraging the interchange of research students between the United Kingdom and certain European countries, and has set aside a number of its research studentships for this purpose. Those awarded such studentships for study in Europe will receive maintenance allowances, second-class rail fare and fees ; in addition, a cost-of-living allowance will be paid for certain countries. The award is tax-free. The duration of the award, and other conditions, are the same as those for ordinary Department of Scientific and Industrial Research studentships. Applications for these awards must be made through heads of departments of science and technology in universities and colleges before July 1 .

\section{Grants to Students}

The National Union of Students has published a Grants Year Book (pp. 107. London: National Union of Students, 1958. 3s.) giving details of awards to students by nearly all the local education author. ities of Great Britain. Besides information about the scale of awards, allowances for vacations and dependants, the book also provides details of how awards are made, the policies of local education authorities to students who fail examinations and other relevant items. A copy of the Ministry of Education Regulations for State Scholarships is also included ; this sets out the income scale for assessing parental contributions. The book should be of practical value to all students and their parents or guardians.

\section{The Salters' Institute of Industrial Chemistry}

The Worshipful Company of Salters, through its Institute of Industrial Chemistry, has since the foundation of the Institute in 1918 devoted its resources mainly to the award of postgraduate research grants. Ninety-eight research students have been awarded fellowships and most of them have had distinguished careers in industry and the universities. In 1951 the award of a research scholarship was instituted, and twenty-eight students have since been elected, including three to scholar ships reserved for students from the Commonwealth. A considerable number of smaller grants have also been awarded each year to part-time students of chemistry in London, and many of the chemical engineering departments of universities throughout Britain have received substantial grants for the purchase of equipment or similar purposes. Arrangements have now been made with the Royal Institution for the Company to sponsor lectures to school-children in some of the interesting branches of chemistry, on the lines of the lectures on 